\title{
Use of Internet for Education Learning among Female University Students of Punjab, Pakistan
}

\author{
Ghulam Safdar ${ }^{1, *}$, Muhammad Naeem Javed ${ }^{2}$, Salman Amin ${ }^{3}$ \\ ${ }^{1}$ Department of Arts \& Media, Foundation University Islamabad (Rawalpindi Campus), Pakistan \\ ${ }^{2}$ School of Media \& Communication Studies, University of Management \& Technology, Pakistan \\ ${ }^{3}$ Department of Arts \& Media, Foundation University Islamabad, Pakistan
}

Received April 3, 2020; Revised May 14, 2020; Accepted June 4, 2020

Copyright $\mathrm{O} 2020$ by authors, all rights reserved. Authors agree that this article remains permanently open access under the terms of the Creative Commons Attribution License 4.0 International License

\begin{abstract}
Current era is called era of internet technology. Internet provides platform where various channels are just one click far away. The core aspire of this research study was to explore internet use for educational learning targeting public universities female students belonging to Punjab Pakistan. The study recorded student's internet usage pattern, level of usage, preferred viewing sites, favorite visiting sites, and most usage time and core reasons of using internet. It also analyzed demographic information of respondents such as hostelries or home, class and urban or rural areas. The study crossed checked the opinion regarding internet usage as well as demographic characteristics. The data was collected using survey methodology. A total sample size of $\mathrm{N}=1157$ respondents were taken from six selected public sectors universities with highest student statistical rate using multi-level sample technique. The collected data was analyzed using SPSS and study focused how female university students think about internet as a medium of educational learning at undergraduate, graduate and post-graduate level. The study concluded that internet usage is more common and is the source of inspiration among female for educational learning and enhanced learning trends and searching educational content. Using internet causes dual learning i.e. educational and technological for female and due to multimedia content, internet is a more effective source of learning for female than text books.
\end{abstract}

Keywords Internet, Educational Learning, Female University Students, Punjab Province

\section{Overview of Internet}

The concept of internet in the present age is the worldwide network of communication but the origin of network started from a small level. The first recorded report of social interaction that could be founded through networking was a series of memos written by Licklider in August 1962. In these memos, he discussed the concept of "Galactic Network" (Licklider, 1962). He envisioned a worldwide organized set of computers through which each person could rapidly access programs and data from any location. This wonderful concept caused the shape of today's internet. Licklider was the first one who heads the computer research program of DARPA started in October, 1962 (Proceeding of IEEE, 1978).

Another major step was to make computer able to talk with each other. To explore this, practically, Thomas Merrill and Roberts connected computers at a long distance with low speed dial-up telephone connection. In fact, it was small but first Wide Area Network (WAN) ever built (Robert \& Merrill, 1966). This trial realized that computer could work well mutually. Programs and data retrieving as needed on remote machine were made possible but switched telephone system was not enough for this job. At that point, Kleinrock's concept of packet switching was adopted and in 1966 Roberts went to DARPA to made concept of computer network more quickly and put this plan together with ARPANET published in 1967 (Roberts, 1967).

\section{Growth of Internet}

Internet is an assortment of communities and its achievement is greatly attributable to fulfilling community needs as well as engaging community in an efficient way to drive the infrastructure forward. It is recognized that in the late 1970s, expansion of internet was accompanied due to enlargement in size of paying attention to research community and coordination among them. Vint Cerf of DARPA formed various coordination bodies to work together for expansion of internet and work on satellite communication including European countries. In 1983, it was recognized that continuous expansion of internet 
community demanded reformation of mechanisms to expend the network. Growth in demand of internet, upgrades standard process itself. Since 1980s to day today, internet grew further than its main research roots to include widely spread user community and enlarged business-related activities (Leiner, 2009).

Increased concentration paid to make process open and fair. This renowned concept of joining to internet is needed to support community needs and ultimately internet led to the formation of internet society in 1991. Communication with the use of optical fiber was initially developed for telephone system but experienced to connect computers through fiber technology which primarily caused rapidly rising demand of internet connectivity in late 1990s. Since that time, internet has been rising at extraordinary rates. So, due to the multitalented which penetrate intensely into the economy, it is affecting all societies, hence it has attracted excessive amount of public attention (Coffman \& Odlyzko, 2001).

During 1980s and early 1990s the internet enjoyed stability and continuous growth. In 1989, Tim Berners Lee of European Organization for Nuclear Research wrote plan for establishing worldwide hypertext system with the recommended name MESH (Berner, 1989). Over next several years, his work from suggestion to verifiable prototype to fully fledged system was on its way. But the cover was finally blown off the comparatively satisfied growth of internet in the mid 1990s; the World Wide Web (WWW) became available to millions of people round the globe.

It was Mosaic (a user friendly web browser, recently named "Netscape") created in March 1994 by team members of university of Illinois with the leadership of Marc Andreesen. At the moment, all previous working styles about proper use of internet reserve concerning its commercialisation become debatable issue because existing setups of governments and academics efforts were compressed by incoming rush of interest from every sector. Till November 2000, internet user calculations reached to 407.1 million and from them 113.14 million were estimated in Europe. Apparently, usage and size figures increased quickly and internet enable users to visit more sites for latest data (Cerf, 1993).

\section{World Wide Web (WWW)}

The World Wide Web merely Web is worldwide information medium which allows users to read, write, upload and download using computers linked to internet. Sometimes the term web is used for internet itself but it is a facility that operates over the internet just as shopping, email or online reservation etc. Web is a global information system and the history of internet goes back further than WWW (Berners, 2000).

The history of World Wide Web goes back to the development of hypertext or computer aided reading of electronic documents and secondly the development of internet protocols made it possible for large global network (Cailliau, 1995). Hypertexts are linked pages to access information of different kinds of websites in which users can browse at their own will. These hypertexts provides single user interface to large classes of information such as database, notes, reports, audio, video, graphics and online help. WWW has two phases, first making use of existing hardware and software including web browser at user's workstation and second extensions of application areas by allowing users to add new materials (Berners et al., 1992).

Software program that is used to access web pages is called browser. While starting a browser, user needs to enter web address of own choice in the address bar of the browser. Web address is also called domain name, IP address or Uniform Resource Locator (URL) (McCahil et al., 1992). This web address is also called hypertext that is linked with another page. Any home page of a website is further linked with another page, in this way different web pages of related data make different websites. These hypertext links are selected by using mouse, pen like device stylus or simply by the touch of fingers. When user selects any reference, the browser presents the linked page or text that it refers to (Berners, Cailliau \& Groff, 1992).

Hypertext system went through various phases of progress and devoted research efforts. Now, World Wide Web has become the backbone which links huge quantity of hypermedia and hypertext documents uploaded or published by communities or persons working from the entire globe (Alomar, 2015).

World Wide Web is the faculty to publish or access data on widely connected computers like devices around the world. The concept of WWW was developed in 1989-90 (Andrew et al., 1996; Kappe, 1993; Fountain et al., 1990). The credit of development of World Wide Web goes to Tim Berners Lee and his team who were working in CERN laboratory, Switzerland (Andrew et al., 1996; Hall, 2011). World Wide Web is open hypermedia that allows us to use and process data from one system to other system without any limit and implies the opportunity to access them using any browser (Davis et al., 1992). For accessing a web page, browser is its entry point, so after the development of web, several browsers were made and they were free of charge, easy to use and had simple user interface (Ehmayer et al., 1997). In 1993, after Mosaic's development, internet explorer and Netscape were developed to access web pages (Andrew et al, 1996; Berner-Lee et al., 1994)

Due to World Wide Web as an open source, browsers are available that have the ability to talk with servers and display all types of documents including text, graphics, audio and videos consisting of simple and easy interfaces to perform functions in different platforms. There were no entry barriers on Web as in other types of networks such as Hyper-G and Microcosm (Andrew et al., 1994; Ehmayer et al., 1997; Berner-Lee \& Cailliau, 1992). Berners's simple idea of 404 errors allowed web to grow without the need to ensure that each server has valid end point and allow others servers to participate and publish data more freely (Davis, 
1999; Lawrence et al., 2001).

On the web people have freedom to upload whatever they want to see on web without any restriction or writing documents of best quality or scientific valuation of their work before publishing (Donato, 2005). Linked web pages take much less amount of space due to the best coding language. Hyperlinks are achievable that help in resulting to know about how related the documents are linked together which contributes to build a website (Carr et al., 1999; Gronback et al., 2000). From start till now, web is free to access using browsing software that is also available and free of charge. Due to the free and wide levels of access, web is more valuable among users and has caused increase in volume of data created in this network. As the popularity grow, more people started to contribute and take benefit of resources accessible on the web. For using web, users are not required to take training course or do many attempts in order to learn its basics (Berners-Lee, 1994; Bouvin, 1999).

Availability of browser allows people to view contents published on web. Browser is the gateway to enter the web. Due to web and the use of browser, people have become able to access and become a part of web in its growing. Apart from that, interoperability of web contributed to its success by allowing client server to talk with various platforms flawlessly. It is easier to access web page by naming its address rather than its location. Due to common addressing system, web structure has become more strong and made public able to provide address of any web that he wish to visit (Berners-Lee, 1994).

Another powerful feature of web is the transformation of any kind of manuscript formats and this quality is facilitated by Hypertext Transfer Protocols (HTTP). It is the standard that is used to transfer data on internet among servers and clients. For communication among clients and servers, powerful language Hypertext Markup Language (HTML) gives this facility. Not only this language could force server to store HTML format documents but also communication of graphics, audio and video could be done easily by this language (Berner-Lee, 1994; Ashman \& Rosemary, 1999). For reducing communication barriers between incompatible systems, TCP/IP protocols are used that allow web to communicate with other platforms that uses the same underlying protocols.

\section{Current Scenario of Internet}

In the present day, internet is the world's largest network. Through this facility billions of people are connected round the globe. Now, not only computers but also computer-like devices are available in variety of shapes and are connected with through internet. The facility of World Wide Web have make internet more fruitful due to the freedom of downloading and uploading data of user's interests. Before the 1990's internet was limited scope and was in the ownership of some dominant companies. Users get access limited data in limited way. But the development of WWW by Burners-Lee created revolution in networking by giving freedom to users to upload and download information from anywhere in the world.

Information technologies, internet and computers have extraordinarily influential tools. These tools have powerful potential to both benefit and harm societies that hug them. On the bright side, internet has been used to improve business, education and create meeting places even participants are away from each other. But on the minus side, these technologies have also been produced new avenue for theft, fraud, distribution of pornography, hate speech and invasion of privacy (Toor, 2003; Safdar \& Khan, 2018).

In the recent decade life without information communication technologies seems as profound and picturesque as an era before sliced bread. Now youth of today have instant access to human knowledge and information just through a click of mouse or a touch of finger (Safdar, Shabir \& Khan, 2018). This facility sometimes, provides unparalleled opportunities for global connection, learning and innovation as never before. Along with threats, internet also best showed numerous benefits as it means not only the potential for persistent and presenting new ideas but also unpredictable challenges for young people (Swanbrow, 2010; Rallings, 2015).

Now internet is a huge collection of concepts that provides data and information from societies to individuals round the clock. From email to video conferencing, print media electronic media, advertising to e-commerce, and increasing friend's list from all over the world is facility provided by the internet. Here are some mostly used services among every age group of individuals.

\section{Internet for Educational Learning}

Internet is not a new source for students and scholars to get educational material. Since last three decades, internet has become a significant source of information that contains vast quantities of information that provide a great deal of regarding its contents, reliability, aim and target groups. So, it is imperative that user should be aware of miscellaneous information available on the internet (Chapman, 2002; Shabir et al., 2014b). The marvellous growth in telecommunication technology has brought online service. Internet's facility of email, websites and information about any topic has promoted our lives and education. Internet offers environment in which millions of people get engaged in the creation and swap of information (Rose \& Fernlund, 1997; Shabir et al., 2014c).

Students have the opportunity to use internet to seek and get scholarly material and therefore, facts on how efficiently they make use of this channel. Students use internet to access libraries, online books, journals, and any other educational material while making their assignments and theses. The majority of users prefers to access internet to get information from e-books, e-journals, and e-newspapers which are more convenient as hard copy (Safdar, Khan \& Abbasi, 2018). By using internet getting 
educational material is easy as there is no need to go library, wasting time in searching relevant book, journal or purchase books, and journals or order expensive newspaper. Saving time and expense is the main factor for every individual. The easy way of searching accurate material has made internet most influential for students and according to survey, till $200050 \%$ of scholarly publication were obtained from the internet (Tenopir et al. 2003; Fescemeyer, 2000).

Internet has become very popular in almost all areas of lives as well as in education in last two decades. The use of internet in schools, colleges and universities has been increased over the last ten years (Berson, 2000; Hassan et al., 2019). Computers with multimedia capabilities are new tools that can transfer education (Van Horn, 1991). Computer can solve many complex problems that teachers usually face and it enables teachers to customize educational material for students (McKeown, 1991). Most university teachers use internet to get tutorial as Chiwepa (2003) discovered that in Zambia University almost 95\% teachers were using internet to get material for students and respondents argued that internet is a tool to get quick and useful information for students. Another research Bao (1998) found that 10\% respondents from Seton Hall University were not the users of internet while $90 \%$ teachers and students were regular users of internet.

The research of Jagdoro (2004) concluded that internet usage is a more frequent activity among university students. For internet usage, students usually prefer cyber café in universities and library to get access to internet, where much less number of students prefer their own personal internet connection. Since the late 1990s, the use of email and online suffering has been increased among under graduate students (Hendel \& Harrold, 2004). This internet usage has both positive and negative impacts on students (Morgan \& Cotton, 2003). Internet has caused broadened and strengthened direct personal relationship (Wellman and Gulia, 1999). Internet usage among university students decreased depression and got social support (LaRose et al. 2001). Internet also promotes more equitable social interaction among individuals belonging to various backgrounds (Janet \& Ann, 2002). Virtual interaction decreased face to face interaction, which causes social isolation and depression (Subramaniam et al. 2008).

Internet has brought advancement in the world of information technology and has become constructive gadget to make this world a global village. From various researches, it has been proved that internet has great impacts on student's social and educational life (Asdeque et al. 2010; Khan, Safdar \& Ashraf, 2018).

\section{The Present Study}

The present study dealt with the internet use for educational learning among young Pakistani women. In Pakistan, from Islamic point of view, every parent tries to educate their children especially daughters for their better future. Study was hypothesized that internet use is the source of inspiration towards learning (H1); Internet use enhanced learning trends (H2); Internet is a reliable source for searching educational content (H3); Internet use causes dual learning (educational \& technological) (H4); Multimedia learning is more effective than text books (H5).

\section{Method}

Current research study dealt with survey method as research design. From four provinces of Pakistan, Punjab is the largest province of Pakistan in population as 53\% of total population lives in Punjab (PBS, 2018). Current research study conducted in six highest student enrolled public universities of Punjab Pakistan.

Table 1. Selected Public Sector Universities in Punjab (Region Wise)

\begin{tabular}{ccc}
\hline Sr. No. & University & Area \\
\hline 1 & The Islamia University of Bahawalpur. & Southern \\
2 & Bahaddin Zakariya University Multan. & Punjab \\
3 & Punjab University Lahore. & \\
4 & Agriculture University Faisalabad. & Central \\
5 & Sargodha University, Sargodha. & Punjab \\
6 & Arid Agriculture University, Rawalpindi. & North \\
& & Punjab \\
\hline
\end{tabular}

Of the six selected public sector universities, two universities were selected from South Punjab, three from Central Punjab and one from North Punjab. In this way, researcher kept in mind that representation from three sides of Punjab equally on the basis of students enrolled in universities i.e. Islamia University of Bahawalpur from South Punjab, Punjab University Lahore, Sargodha University Sargodha and Agriculture University Faisalabad from Central Punjab and Arid Agriculture University from North Punjab.

\section{Procedure}

\section{Sample \& Technique}

Current research study consisted on multi stages sampling technique. At the first stage, the researcher used purposive technique to select the top enrolled public sector universities of Punjab in which two universities from south, three from centre and one from north Punjab were selected. At the second stage, the researcher used purposive sampling to select faculty and at the third stage, the researcher used random sampling to selects five departments from each faculty for data collection.

The targets of study were female university students from classes ranging $\mathrm{BS}$ level to $\mathrm{PhD}$ level. Questionnaire was distributed among 1300 respondents (depending upon enrolled statistics in each department). In return, 1157 questionnaires were returned. In this way response rate was $89 \%$. 
Table 2. Selected Public Sector Universities/DAI's in Punjab

\begin{tabular}{|c|c|c|c|c|}
\hline Sr. & Name of University & $\begin{array}{l}\text { Student's } \\
\text { Statistics }\end{array}$ & $\begin{array}{c}\text { Respondents per } \\
\text { University }\end{array}$ & Students per Area \\
\hline 1 & Bahauddin Zakariya University Multan & $\begin{array}{c}21444 \\
17.35 \%\end{array}$ & 226 & $\begin{array}{c}\text { Southern Punjab } \\
424\end{array}$ \\
\hline 2 & Islamia University of Bahawalpur & $\begin{array}{c}18807 \\
15.22 \%\end{array}$ & 198 & $32.61 \%$ \\
\hline 3 & University of Punjab Lahore & $\begin{array}{c}32481 \\
26.28 \%\end{array}$ & 342 & \multirow{3}{*}{$\begin{array}{c}\text { Central Punjab } \\
783 \\
60.23 \%\end{array}$} \\
\hline 4 & University of Sargodha & $\begin{array}{c}22219 \\
17.98 \%\end{array}$ & 234 & \\
\hline 5 & University of Agriculture Faisalabad & $\begin{array}{c}19705 \\
15.94 \%\end{array}$ & 207 & \\
\hline 6 & Arid Agriculture University Rawalpindi & $\begin{array}{c}8895 \\
7.19 \%\end{array}$ & 93 & $\begin{array}{c}\text { North Punjab } \\
93 \\
7.15 \%\end{array}$ \\
\hline \multicolumn{2}{|c|}{ Total population of selected Universities } & $\begin{array}{c}123551 \\
100 \%\end{array}$ & 1300 & $\begin{array}{c}1300 \\
100 \%\end{array}$ \\
\hline
\end{tabular}

Table 3. Demographics of Respondents

\begin{tabular}{|c|c|c|c|c|}
\hline Sr. No. & $\begin{array}{c}\text { Demographic } \\
\text { Characteristics } \\
\end{array}$ & Description of Characteristics & $\mathbf{F}$ & $\%$ \\
\hline \multirow{7}{*}{1} & \multirow{7}{*}{ University } & Punjab University Lahore & 295 & 25.5 \\
\hline & & Agriculture University Faisalabad & 188 & 16.2 \\
\hline & & Sargodha University Sargodha & 213 & 18.4 \\
\hline & & Bahauddin Zakariya University Multan & 198 & 17.1 \\
\hline & & Islamia University Bahawalpur & 172 & 14.9 \\
\hline & & Arid Agriculture University Rawalpindi & 91 & 7.9 \\
\hline & & Total & 1157 & 100.0 \\
\hline \multirow{3}{*}{2} & \multirow{3}{*}{ Background } & Urban & 734 & 63.4 \\
\hline & & Rural & 423 & 36.6 \\
\hline & & Total & 1157 & 100.0 \\
\hline \multirow{5}{*}{3} & \multirow{5}{*}{ Class } & BS & 564 & 48.7 \\
\hline & & $\mathrm{MA} / \mathrm{MSC}$ & 374 & 32.3 \\
\hline & & M.Phil & 172 & 14.9 \\
\hline & & $\mathrm{PhD}$ & 47 & 4.1 \\
\hline & & Total & 1157 & 100.0 \\
\hline \multirow{3}{*}{4} & \multirow{3}{*}{ Residence } & Hostel & 458 & 39.6 \\
\hline & & Home & 699 & 60.4 \\
\hline & & Total & 1157 & 100.0 \\
\hline
\end{tabular}

\section{$\mathrm{N}=1157$}

The above table shows the demographics of respondents. Demographics of respondents include university to whom they belong as data were collected from six universities of Punjab Pakistan. Respondent's background i.e. rural or urban, class from $\mathrm{BS}$ to $\mathrm{PhD}$ and residence that either students come from home daily or hostelries.

\section{Measures}

The data collection tool (questionnaire) was designed in
Urdu (National Language) for data collection. It seemed necessary to reduce complexity of understating questions among the respondents. After data collection, tool was again translated into English language for processing in SPSS and data presentation.

Internet use is the source of inspiration towards learning: Respondents were asked to answer what they think about that internet use is the source of inspiration towards learning. ( $1=$ Yes, $2=\mathrm{No}, 3=\mathrm{To}$ some extent). Results of exploratory factor analysis showed that three 
items were loaded in a single factor. The items showed high reliability and were average created scale $(M=1.66$, $\mathrm{SD}=.910$ ).

Internet use enhanced learning trends: Respondents were reported to answer what they think about that internet use enhanced learning trends. $(1=\mathrm{Yes}, 2=\mathrm{No}, 3=\mathrm{To}$ some extent). Results of exploratory factor analysis showed that three items were loaded in a single factor. The items showed high reliability and were average created scale $(\mathrm{M}=1.94, \mathrm{SD}=.841)$.

Internet is a reliable source for searching educational content: Respondents were reported to answer what they think about that internet is a reliable source for searching educational content. $(1=$ Yes, $2=$ No, $3=$ To some extent $)$. Results of exploratory factor analysis showed that three items were loaded in a single factor. The items showed high reliability and were average created scale $(\mathrm{M}=2.04$, $\mathrm{SD}=.871$ ).

Internet use causes dual learning (educational \& technological): Respondents were reported to answer what they think about that internet use causes dual learning (educational \& technological). ( $1=\mathrm{Yes}, 2=\mathrm{No}, 3=$ To some extent, 4=Don't know). Results of exploratory factor analysis showed that four items were loaded in a single factor. The items showed high reliability and were average created scale $(\mathrm{M}=2.49, \mathrm{SD}=1.083)$.

Multimedia learning is more effective than text books: Respondents were reported to answer what they think about that multimedia learning is more effective than text books. ( $1=$ Yes, $2=$ No, $3=$ To some extent). Results of exploratory factor analysis showed that three items were loaded in a single factor. The items showed high reliability and were average created scale $(\mathrm{M}=1.64, \mathrm{SD}=.864)$.

Control Variables. University, background, class, residence and overall use of internet were used as covariates. Respondents were asked to report their universities (1=Islamia University, 2=Bahauddin Zakariya University, $3=$ Punjab University, $4=$ Agriculture University, $5=$ Sargodha University, $6=$ Arid University $)(\mathrm{M}=3.03$, $\mathrm{SD}=1.630)$. In addition class variable i.e. $(1=\mathrm{BS}, 2=$ Master, $3=$ MPhil, $4=\mathrm{PhD})(\mathrm{M}=1.74, \mathrm{SD}=.856)$ were controlled because this variable was found to be associated with internet use. Background variable was associated with rural or urban (1=Urban, $2=$ Rural $)(\mathrm{M}=1.63, \mathrm{SD}=.482)$ as this variable was also associated with different levels of educated families and residential environment related to $(1=$ Home, $2=$ Hosteller $)(\mathrm{M}=1.60, \mathrm{SD}=.489)$ as this factor associated with freedom to use internet. Finally overall internet use was controlled, considering that if could be closely linked to the variables of interests, including the behaviour of educational grooming. It was measured by reporting three questions regarding the frequency of usage of internet ( $1=$ Daily, $2=$ Three days in a week, $3=$ According to need) $(\mathrm{M}=1.86, \mathrm{SD}=.969)$ and time spend on internet ( $1=\mathrm{Up}$ to two hours, $2=\mathrm{Up}$ to two to four hours, $3=$ More than four hours) $(\mathrm{M}=1.94, \mathrm{SD}=.837)$ and timing of using internet (1=Morning $8 \mathrm{AM}$ to $12 \mathrm{PM}, 2=$ Afternoon $12 \mathrm{PM}$ to $4 \mathrm{PM}, 3=$ Evening 4 PM to $7 \mathrm{PM}, 4=$ Night $7 \mathrm{PM}$ to 12 $\mathrm{AM})(\mathrm{M}=3.13, \mathrm{SD}=.976)$. 


\section{Results}

Table 4. Mean, Standard Deviation, P-value and association of assumed hypothesis (H1)

\begin{tabular}{|c|c|c|c|c|c|c|}
\hline Hypothesis & Means & Std. Deviation & Person Chi-Square & Df & P-Value & Association \\
\hline Internet use is source of inspiration towards learning & 1.71 & .922 & $35.276^{\mathrm{a}}$ & 2 & .000 & Significant \\
\hline
\end{tabular}

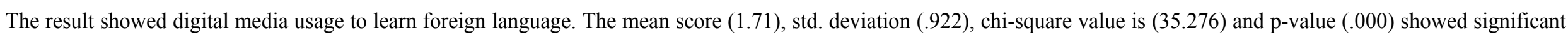
association among assumed hypothesis at $<0.05$ level. Hence the hypothesis (H1) internet use is a source of inspiration towards learning supported.

\begin{tabular}{|c|c|c|c|c|c|c|}
\hline Hypothesis & Means & Std. Deviation & Person Chi-Square & Df & P-Value & Association \\
\hline Internet use enhanced learning trends & 1.62 & .832 & $33.761^{\mathrm{a}}$ & 2 & .000 & Significant \\
\hline
\end{tabular}

Significant P-value at $<0.05$

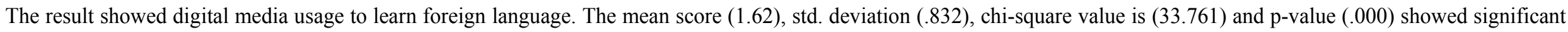
association among assumed hypothesis at $<0.05$ level. Hence the hypothesis (H2) internet use enhanced learning trends supported.

Table 6. Mean, Standard Deviation, P-value and association of assumed hypothesis (H3)

\begin{tabular}{|c|c|c|c|c|c|c|}
\hline Hypothesis & Means & Std. Deviation & Person Chi-Square & Df & P-Value & Association \\
\hline Internet reliable source for searching educational content & 1.49 & .811 & $29.116^{\mathrm{a}}$ & 2 & .000 & Significant \\
\hline
\end{tabular}

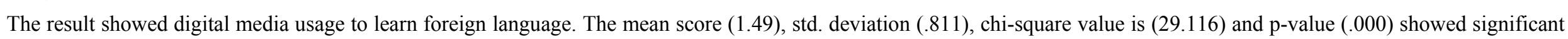
association among assumed hypothesis at $<0.05$ level. Hence the hypothesis (H3) internet is a reliable source for searching educational content supported.

Table 7. Mean, Standard Deviation, P-value and association of assumed hypothesis (H4)

\begin{tabular}{|c|c|c|c|c|c|c|}
\hline Hypothesis & Means & Std. Deviation & Person Chi-Square & Df & P-Value & Association \\
\hline Internet use causes dual learning (educational \& technological) & 1.60 & .837 & $23.115^{\mathrm{a}}$ & 2 & .001 & Significant \\
\hline
\end{tabular}

Significant P-value at $<0.05$

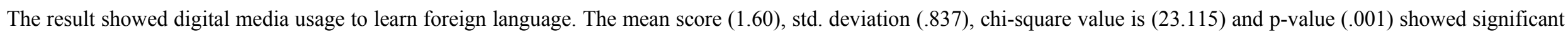
association among assumed hypothesis at $<0.05$ level. Hence the hypothesis (H4) internet use causes dual learning (educational $\&$ technological) supported.

Table 8. Mean, Standard Deviation, P-value and association of assumed hypothesis (H5)

\begin{tabular}{|c|c|c|c|c|c|c|}
\hline Hypothesis & Means & Std. Deviation & Person Chi-Square & Df & P-Value & Association \\
\hline Multimedia learning is more effective then text books & 1.44 & .840 & $27.555^{\mathrm{a}}$ & 2 & .001 & Significant \\
\hline
\end{tabular}

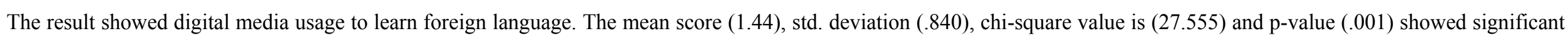
association among assumed hypothesis at $<0.05$ level. Hence the hypothesis (H5) multimedia learning is more effective than text books supported. 


\section{Discussions}

Current research study dealt with the use of internet for education learning among female university students of Punjab, Pakistan. In this era internet has become a popular and powerful tool with benefits and drawbacks. In Pakistan, the ratio of female in society and education is high. Advancement in technology and free access to internet attracted all the members of society especially youth. Internet for students is just like sea where searching educational material concerning different topics is not only easy but also fast as search engines filter required data in a moment. As Shabir et al, (2014a) said, since last two decades internet has become a significant source of information about any topic. Chapman (2002) internet is a world where miscellaneous information is available round the clock. Rose \& Fernlund (1997) stated that internet has promoted our lives and education where people swap information and participate in topics of interests. In this developed era, there is no need to go library, find books of interest, making himself bound for a while to read material. This difficulty internet has been eliminated and educational material about any topic is now in everyone's access round the clock on their own way. Berson (2000) argued in his research that internet has become very popular among university students in two decades. The popularity and importance of internet has been discussed by hundreds of researchers in the world as this facility has made it much fast for students to access data online. Jagdoro (2004) also concluded that internet usage is a more frequent activity among university students. The same experience has been noticed in Pakistani universities as almost all the students studying in universities frequently access to internet for their educational and social relationship. The topic of concern verified that internet has captured all the aspects of student's lives and has positive impacts on their educational career.

\section{Conclusions}

The study concluded that internet is the most favourite tool among university students especially female and they are regular user of internet. Since morning time to late night, internet connectivity is vital elements among youth. For any kind of information especially educational learning, internet is a more frequently used tool for students. Internet is the source of inspiration towards e-learning as this facility is available everywhere without time and geographical limit. It is also revealed that due to frequent use of internet, learning trends have enhanced among university students. Educational content available on internet is reliable as a variety of sources gives the educational material with more research evidence. Searching educational content on internet promotes not only female student's grades but also technological learning. With the variety of online content like video, audio, pictorial and text, internet is a more effective way of learning for female students as compared to text books. More involvement in online communication, text messages and searching material has been proved fruitful in frequent use of English language.

\section{REFERENCES}

[1] Alomar N. N. (2015). The World Wide Web, Hyper-G and Microcosm: Historical Analysis and Future Integration Directions. International Journal of Computer Applications. Volume 115, No.11, Pp.33-36

[2] Andrews, K. et al. (1994). "Hyper-G: A new tool for distributed hypermedia." In International Conference on Distributed Multimedia Systems and Applications.

[3] Andrews, K., Kappe, F. and Maurer, H. (1996). "The Hyper-G network information system." J. UCS the Journal of Universal Computer Science. Springer Berlin Heidelberg, 206-220.

[4] Asdeque M.M., Khan M.N., Rizvi S.A.A. (2010). Effect of internet on the academic performance and social life of university students $\mathrm{n}$ Pakistan. Journal of Education and Sociology. Pp.21-27

[5] Ashman, H., and Rosemary M. S. 1999. "Computing surveys' electronic symposium on hypertext and hypermedia: editorial." ACM Computing Surveys (CSUR) 31.4es: 1.

[6] Bao, X. (1998). Challenges and opportunities: a report of the 1998 library survey of internet users at Seton Hall University. College and Research Libraries 59(6): 535-543.

[7] Berners-Lee T. \& Cailliau R. Groff J.F., Pollermann B. (1992). World-Wide Web: The Information Universe. Electronic Networking, Vol. 2, No. 1, pp. 52-58

[8] Berners-Lee T.J., Cailliau R. \& Groff J.F. (1992). The World Wide Web. Computer networks and ISDN System. Pp.454-459.

[9] Berners-Lee, T. and Cailliau, R., 1992. "The World- Wide $W e b^{\prime \prime}$, in proceedings of the conference" Computing in High Energy Physics", Annecy, France. Yellow report, CERN, Geneva, Switzerland

[10] Berners-Lee, T., Cailliau R., Luotonen, A., Nielsen, H. F., and Secret, A.. (1994). "The World-Wide Web." Commun. ACM 37, 8 (August 1994), 76-82.

[11] Berners-Lee, Tim (1989). Information Management: A Proposal. March 1989. http://www.w3.org/History/1989/pr oposal.html

[12] Berners-Lee, Tim (2000). Weaving the Web: The Original Design and Ultimate Destiny of the World Wide Web. San Francisco: Harper. p. 23. ISBN 9780062515872.

[13] Berson, M.J. (2000). Effectiveness of computer technology in the social studies: A review of the literature. Journal of Research on Computing in Education, 2 (4), 486-499.

[14] Berson, M.J. (2000). Effectiveness of computer technology in the social studies: A review of the literature. Journal of 
Research on Computing in Education, 2 (4), 486-499.

[15] Bouvin, N. O. (1999). "Unifying strategies for Web augmentation." Proceedings of the tenth ACM Conference on Hypertext and hypermedia: returning to our diverse roots: returning to our diverse roots. ACM.

[16] Cailliau R. (1995) Text of a speech delivered at the launching of the European branch of the W3 Consortium, Paris.

[17] Carr, L., Hall, W., and Roure, D. D. (1999). "The evolution of hypertext link services." ACM Computing Surveys (CSUR) 31.4es: 9.

[18] Cerf, Vinton (1993). "How the Internet Came to Be," as told to Bernard Aboba. c1993. http://www.netvalley.com/archiv es/mirrors/cerf-how-inet.txt.

[19] Chapman, L. (2002). Russian roulette or Pandora's box: use of Internet as a research tool. Paper presented at VALA 2002. 11th Biennial Conference and Exhibition, 6-8 Melbourne. Victoria, Australia.

[20] Chapman, L. (2002). Russian roulette or Pandora's box: use of Internet as a research tool. Paper presented at VALA 2002. 11th Biennial Conference and Exhibition, 6-8 Melbourne. Victoria, Australia.

[21] Chiwepa V (2003). The use of the internet and internet by teaching staff of the University of Zambia. Afr. J. Archives Inf. Sci. 13(2): 119-132.

[22] Coffman K. G. \& Odlyzko A. M. (2001). The size and growth rate of the Internet. http://firstmonday.org/ Also available at $\square \mathrm{http}: / / \mathrm{www}$. research.att.com/amo

[23] Davis, H. C. (1999). "Hypertext link integrity." $A C M$ Computing Surveys (CSUR) 31.4es: 28.

[24] Davis, H. C., Hall, W., Heath, Ian, Hill, Gary J. and Wilkins, Robert J. (1992). "MICROCOSM: An Open Hypermedia Environment for Information Integration."

[25] Donato, F. D. (2005). "Designing a Semantic Web Path to e-Science." SWAP.

[26] Ehmayer, G., Kappel, G., and Reich, S. (1997). "Connecting databases to the Web: A taxonomy of gateways." Database and Expert Systems Applications. Springer Berlin Heidelberg.

[27] Fescemeyer, K. (2000). Information-seeking behavior of undergraduate geography students. Research Strategies, 17(3/4):307-317.

[28] Fountain, A. M., et al. (1990). "MICROCOSM: An Open Model for Hypermedia with Dynamic Linking."

[29] Gronback, K., Sloth, L., and Bouvin, N. O. (2000). "Open hypermedia as user controlled meta data for the Web." Computer Networks 33.1: 553-566.

[30] Hall, W. (2011). "The ever evolving web: the power of networks", International Journal of Communication $5,651-664$

[31] Hassan T.U., Shabir G., Safdar G., Hussain J.M. (2019) "Social Media Defy Spiral of Silence Theory and Provides Baseline for new Spiral of Social Media Theory: Ground Perspective" Pakistan Journal of Social Sciences (PJSS),
Vol.39, No.4. Pp.1549-1558. ISSN: 2074-2061

[32] Hendel, D. D., \& Harrold, R. D. (2004). Undergraduate student leisure interests over three decades. College Student Journal, 38(4), 557-568.

[33] Jagdoro KO (2004). A study of internet usage in Nigerian universities: A case study of Obafemi Awolowo University Ile-Ife, Nigeria UNESCO, Paris.

[34] Jagdoro KO (2004). A study of internet usage in Nigerian universities: A case study of Obafemi Awolowo University Ile-Ife, Nigeria UNESCO, Paris.

[35] Janet, W. S. \& Ann L. D. (2002). Bringing the internet to the school: Lessons from an Urban District. John Wiley \& sons inc.

[36] Kappe, F. (1993). "Hyper-G: A distributed hypermedia system." Proc. INET. Vol. 93.

[37] Khan A.W., Safdar G., Ashraf M. (2018) "Effects of Mobile Phone Usage on Social Behaviours of University Students: A Case study of Islamia University of Bahawalpur, Pakistan”. Global Media Journal Pakistan Edition. Vol.11, No.1. Pp.1-26. ISSN- 2070- 2469

[38] LaRose, R., Eastin, M. S., \& Gregg, J. (2001). Reformulating the Internet paradox: Social cognitive explanations of Internet use and depression. Journal of Online Behavior, 1(2): no pagination specified.

[39] Lawrence, S., et al. 2001. "Persistence of web references in scientific research." Computer 34.2: 26-31.

[40] Leiner et al. (2009). A brief history of internet. $A C M$ SIGCOMM Computer Communication Review. Volume 39, Number 5. Pp22-31.

[41] Licklider J.C.R. \& W. Clark (1962). “On-Line Man Computer Communication,” August 1962.

[42] McCahil M., et al., (1992). The Internet Gopher: An Information Sheet, in: Electronic Networking: Research, Applications and Policy, Vol. 2, No. 1.Pp. 67-71.

[43] McKeown, P. (1991). Living with Computers (3rd ed.). New York: Harcourt Brace Janovich.

[44] Morgan, C., \& Cotton, S. R. (2003). The relationship between Internet activities and depressive symptoms in a sample of college freshmen. Cyber Psychology \& Behavior, 6(2):133-142.

[45] Proceedings of the IEEE, Special Issue on Packet Communication Networks, Volume 66, No. 11, November, 1978. (Guest editor: Robert Kahn, associate guest editors: Keith Uncapher and Harry van Trees)

[46] Rallings J. (2015). Youth and the internet: A guide for policy makers. Barnardo's Registered Charity Nos. 216250 and $\mathrm{SC} 037605$

[47] Roberts L. \& T. Merrill T. (1966). "Toward a Cooperative Network of Time-Shared Computers," Fall AFIPS Conf., Oct. 1966

[48] Roberts L. (1967) "Multiple Computer Networks and Inter-computer Communication," ACM Gatlinburg Conf., October 1967.

[49] Rose S.A., \& Ferlund, P.M. (1997). Using technology for 
powerful social studies learning. Social Education, 61(3):160-166.

[50] Rose, S.A., \& Ferlund, P.M. (1997). Using technology for powerful social studies learning. Social Education, 61(3):160-166.

[51] Safdar G. Khan A.W., Abbasi, A. (2018) "Role of Social Media for Promotion of Education in Southern Punjab". Journal of Education Research. Vol.21, No.1 Pp.73-85. ISSN- 1027- 9776

[52] Safdar G., Khan A.W. (2018) "Effects of Digital Media on Cultural Values of Male University Students of Punjab, Pakistan" Pakistan-Annual Research Journal, Vol.54, Pp.1-19. ISSN: 1990-6579

[53] Safdar G., Shabir G., Khan A.W. (2018) "Media's Role in Nation Building: Social, Political, Religious and Educational Perspectives" Pakistan Journal of Social Sciences (PJSS), Vol.38, No.2. Pp.387-397 ISSN: 2074-2061

[54] Shabir G. Iqbal Y.W., Safdar G. (2014a). Demographics' Differences in Social Networking Sites Use: What Communication Motives Does it Gratify?. International Journal of Social Work and Human Services Practice. Vol.2. No.5 Oct, 2014, pp. 184-194.

[55] Shabir G., Hameed Y.M.Y., Safdar G., Gilani S.M.F.S. (2014c). The Impact of Social Media on Youth: A Case Study of Bahawalpur City. Asian Journal of Social Sciences \& Humanities Vol. 3(4). Pp.132-151.

[56] Shabir G., Safdar G., Imran M. (2014b). Higher Education and its Importance for Citizen: A Comparative Analysis of UK and USA. Research on Humanities and Social. Vol.4, No.25. Pp.17-23.

[57] Subramaniam Mythily, Shijia Qiu, Munidasa Winslow, (2008). Prevalence and Correlates of Excessive Internet Use among Youth in Singapore. Annals Academy of Medicine, Vol. 37 No. 1

[58] Swanbrow D (2010). Empathy: College students don't have as much as they used to. http://ns.umich.edu/new/releases/7 724. Retrieved on 12-04-2018

[59] Tenopir, C., King, D., Boyce, P., Grayson, M., Zhang, Y. \& Ebuen, M. (2003). Patterns of journal use by scientists through three evolutionary phases. D-lib Magazine, 9(5).

[60] Toor J.D. (2003). The Information age. Green Haven Press. The Gale Group, Inc., a division of Thomson Learning, Inc.

[61] Wellman, B., \& Gulia, M. (1999) Virtual communities as communities: Net surfers don't ride alone. In M.A. Smith \& P. Kollock (Eds.), Communities in cyberspace (pp.167-194). New York: Routledge. 